\title{
Analisis Sebaran Padatan Tersuspensi dan Transparansi Perairan Menggunakan Landsat 8 (Studi Kasus: Perairan Bintan, Kepulauan Riau)
}

\author{
Irma'atus Sholihah, Lalu Muhamad Jaelani, Salam Tarigan \\ Teknik Geomatika, Fakultas Teknik Sipil dan Perencanaan, Institut Teknologi Sepuluh Nopember \\ Jl. Arief Rahman Hakim, Surabaya 60111 Indonesia \\ e-mail:Lmjaelani@geodesy.its.ac.id, Saltargir@yahoo.com, Irmaatuss2@gmail.com
}

\begin{abstract}
Abstrak-Perairan Bintan memiliki sumberdaya pesisir dan laut yang sangat potensial untuk wisata bahari dan kehidupan biota laut. Akan tetapi, adanya kegiatan manusia seperti penambangan, pembuangan limbah rumah tangga akan memberikan dampak negatif terhadap penurunan kualitas perairan dan sumber daya pesisir. Faktor utama yang mempengaruhi kualitas perairan pada badan air pada setiap bentang lahan adalah padatan tersuspensi dan transparansi. Analisis padatan tersuspensi dan transparansi menggunakan metode penginderaan jauh dengan didukung data in situ. Data in situ digunakan untuk melakukan validasi data estimasi citra menggunakan NMAE. Pada penelitian ini konsentrasi TSS yang dihasilkan memiliki rentang nilai antara 0-45 mg/l. Sedangkan sebaran nilai transparansinya memiliki rentang nilai antara 3-6 meter. Kondisi TSS dan transparansi tersebut masih berada pada batas yang ditentukan dalam Keputusan Menteri Negara Lingkungan Hidup No 51 Tahun 2004.
\end{abstract}

Kata Kunci-Konsentrasi, NMAE, Transparansi, TSS

\section{PENDAHULUAN}

$\mathrm{K}_{\mathrm{r}}$ ABUPATEN Bintan merupakan sebuah kepulauan di Propinsi Kepulauan Riau yang memiliki luas $1.318 \mathrm{~km}^{2}$ yang terletak di bagian selatan Laut Cina Selatan dan berbatasan dengan Kabupaten Batam dan Singapura [1]. Topografi daratan yang cukup landai, banyak muara sungai dan teluk, membuat kawasan pesisir Kabupaten Bintan memiliki ekosistem pantai pesisir yang lengkap. Perairan ini memiliki berbagai ekosistem laut dangkal yang merupakan tempat hidup dan memijah ikan-ikan laut seperti ekosistem mangrove, lamun dan terumbu karang. Kondisi perairan Bintan Timur mengalami penurunan kualitas disebabkan semakin pesatnya pembangunan di segala bidang serta krisis ekonomi yang berkelanjutan telah memberikan tekanan yang lebih besar terhadap lingkungan sekitarnya, khususnya lingkungan perairannya [1].

Faktor utama yang mempengaruhi kualitas perairan pada badan air pada setiap bentang lahan adalah padatan tersuspensi (TSS, Total Suspended Sediment), kekeruhan air, transparansi (transparansi), klorofil [2]. Faktor-faktor tersebut mengubah karakteristik pantulan atau pancaran suhu air yang dapat diukur dan dideteksi menggunakan teknik penginderaan jauh [3]. Pada umumnya faktor kimia dan bakteriologi tidak secara langsung mempengaruhi perubahan karakteristik spektral pantulan atau pancaran air, sehingga hanya dapat diketahui pengaruhnya secara tidak langsung melalui parameter kualitas air lainnya yang terpengaruh oleh faktor kimia atau bakteriologi tersebut [3].

Analisis tingkat pencemaran air laut dilakukan pendekatan metode penginderaan jauh agar efektif dan efisien. Pada umumnya, sebagian besar sinar matahari yang masuk ke tubuh air jernih diserap pada kedalaman kurang lebih dua meter dari permukaan [3]. Material yang terkandung di dalam air dapat secara siginifikan mengubah karakteristik hamburan balik air tersebut [3]. Teknik penginderaan jauh ialah mendasarkan kepada kemampuan untuk mengukur perubahan pada karakteristik spektral yang dipantulkan dari air dan kemudian membandingkan hasil pantulan tersebut dengan parameter kualitas air [3]. Panjang gelombang yang dapat dengan baik digunakan untuk mengukur parameter kualitas air tergantung kepada material yang hendak diukur atau diketahui konsentrasinya dan karakteristik sensor penginderaan jauh yang digunakan [3].

Penelitian ini menggunakan citra Landsat 8 . Citra Landsat 8 dipilih karena area studi tidak begitu luas dan memilki resolusi spasial yang baik, yaitu 30 meter.

\section{METODE PENELITIAN}

\section{A. Lokasi Penelitian}

Penelitian dilakukan di perairan Bintan Timur. Perairan Bintan terletak di Kabupaten Bintan yang secara geografis terletak antara $0^{\circ} 6^{\prime} 17^{\prime \prime} \mathrm{LU}-1^{\circ} 34^{\prime} 52^{\prime \prime} \mathrm{LU}$ dan $104^{\circ} 12^{\prime} 47^{\prime \prime} \mathrm{BT}$ $108^{\circ} 27^{\prime \prime}$ BT [1]. Luas wilayah Kabupaten Bintan mencapai $88.038,54 \mathrm{Km}^{2}$, luas daratan hanya 2,21\%, sedangkan luas perairan 1.946,13 $\mathrm{Km}^{2}$ [1]. Kecamatan terluas adalah Kecamatan Gunung Kijang dengan luas $344,28 \mathrm{Km}^{2}$ dan kecamatan terkecil adalah Tambelan yaitu $90,96 \mathrm{Km}^{2}$ [1]. Kabupaten Bintan saat ini terdiri dari 240 buah pulau besar dan kecil [4]. Daerah Kabupaten Bintan berbatasan dengan Kabupaten Natuna di sebelah utara, dan berbatasan dengan Kabupaten Liangga di sebelah selatan, berbatasan dengan Kota Tanjung Pinang dan Kota Batam serta berbatasan dengan Propinsi Kalimantan Barat di sebelah timur [1]. 


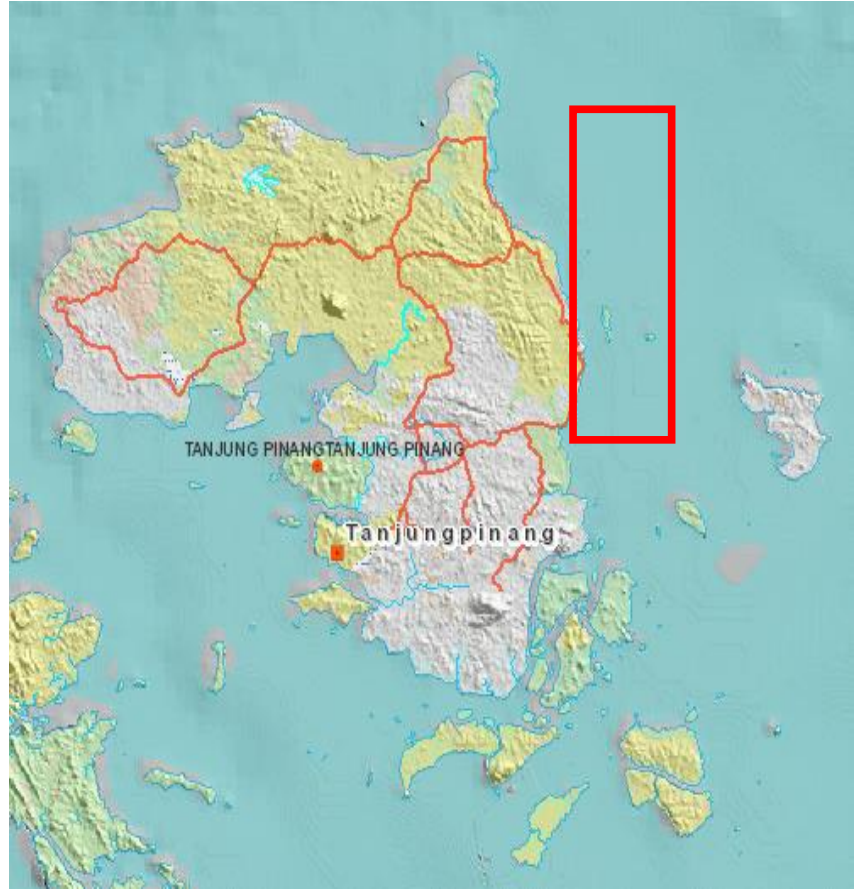

Gambar 1. Peta Lokasi Penelitian

(Sumber: http://tanahair.indonesia.go.id/)

\section{B. Data yang digunakan}

Pada penelitian ini, data yang digunakan adalah data citra Landsat 8 L1T akuisisi tanggal 5 September 2015 dan data pengukuran lapangan oleh LIPI sebanyak 23 titik akuisisi tanggal 3 September 2015. Penelitian ini menggunakan data citra Landsat $8 \mathrm{~L} 1 \mathrm{~T}$ perekaman data tanggal 05 September 2015.

\section{Pengolahan Citra}

- Kalibrasi Radiometrik

Kalibrasi radiometrik bertujuan untuk mendapatkan nilai radiance_toa (Top of Atmospheric) dengan cara mengkonversi nilai citra asli hasil unduhan yaitu nilai digital (DN) menjadi radiance ToA (Top of Atmospheric) [5] menggunakan algoritma:

$L_{\lambda}=M_{L} \times Q_{c a l}+A_{L}$

$L_{\lambda}$ merupakan ToA spectral Radiance, $M_{L}$ merupakan nilai Radiance Mult Band yang terdapat pada metadata, $A_{L}$ merupakan Radiance Add Band pada metadata, sedangkan $Q_{c a l}$ merupakan nilai digital (DN) kanal yang digunakan.

- Koreksi Atmosfer

Koreksi atmosfer dalam penelitian menggunakan parameter koreksi dari hasil simulasi Second Simulation of a Satellite Signal in the Solar Spectrum-Vector (6SV) [5] dengan persamaan:

$$
\begin{aligned}
& y=x a \times L_{\lambda}-x b \\
& a c r=\frac{y}{(1 .+x c \times y)} \\
& R r s_{\lambda}=a c r / \pi
\end{aligned}
$$

acr adalah atmospheric correction reflectance, $L_{\lambda}$ adalah nilai radian $T o A, R r s_{\lambda}$ adalah remote sensing reflectance, dan $x a$, $x b, x c$ adalah koefisien parameter koreksi atmosfer.
- Pengolahan TSS dan Transparansi Perairan

Ekstraksi algoritma dilakukan untuk memperoleh nilai konsentrasi TSS dan transparansi. Pada penelitian ini, algoritma yang digunakan dalam proses ekstraksi terdiri dari masing-masing 3 algoritma, yaitu:

1. Algoritma Jaelani (2015)

Algoritma tersebut menggunakan perbandingan kanal 2 (kanal biru) dan kanal 3 (kanal hijau) dalam format remote sensing reflectance [6].

$$
\log \operatorname{TSS}(m g / l)=1,5212\left(\frac{\log \operatorname{Rrs}(\lambda 2)}{\log \operatorname{Rrs}(\lambda 3)}\right)-0,3698
$$

\section{Algoritma Laili (2015)}

Algoritma tersebut menggunakan perbandingan kanal 2 (kanal biru) dan kanal 4 (kanal merah) dalam format remote sensing reflectance [7].

$$
\operatorname{TSS}(m g / l)=31,420\left(\frac{\log R r s(\lambda 2)}{\log R r s(\lambda 4)}\right)-12,719
$$

\section{Algoritma Parwati (2014)}

Algoritma tersebut menggunakan kanal 4 (kanal merah) merupakan data reflektan yang sudah terkoreksi efek atmosfer [8].

$$
\operatorname{TSS}(m g / l)=3,3238 \times \exp (34,099 \times \rho(B o A)
$$

\section{Algoritma Transparansi Shodiqin (2015)}

Algoritma tersebut menggunakan Reflektan permukaan dari rasio Log kanal 1 dengan log kanal 3 (Log K1 / Log K3) yang di simbolkan dengan $x$ [9].

$$
S D T(m)=1000000000_{e}^{-24,93 x}
$$

\section{Algoritma Transparansi Tarigan (2012)}

Algoritma tersebut menggunakan nilai hasil kromatisi kanal 3 (kanal hijau) dengan format data nilai digital [10].

$$
\begin{aligned}
& \operatorname{SDT}(m)=-159,73 x+57,845 \\
& x=\frac{d n(2)}{(\operatorname{dn}(2)+\operatorname{dn}(3)+\operatorname{dn}(4))}
\end{aligned}
$$

\section{Algoritma Transparansi Chipman (2004)}

Algoritma tersebut menggunakan perbandingan kanal 1 dan kanal 2 dalam format radian

$$
S D T(m)=1,135 \times \frac{L 1}{L 2}-3,193
$$

- Validasi Algoritma

Hasil konsentrasi parameter kualitas perairan dari pengolahan citra di validasi dengan data in situ parameter kualitas perairan menggunakan Normalized Mean Absolute Error (NMAE). Syarat minimum NMAE yaitu sebesar $<30 \%$ [5]. 


\section{- Analisis}

Analisa dari sebaran konsentrasi TSS dan kecerahan terhadap keputusan menteri negara lingkungan hidup no 51 tahun 2004

\section{HASIL DAN ANALISA}

\section{A. Hasil Kalibrasi Radiometrik (Radian-Sensor)}

Setelah nilai digital (ND) di kalibrasi radiometrik didapatkan hasil sebagai berikut:

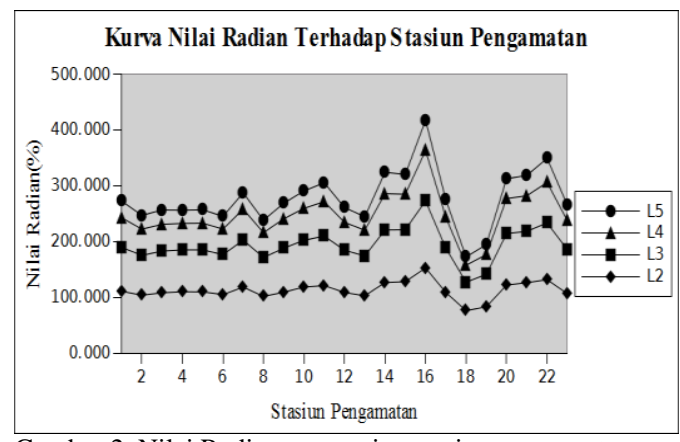

Gambar 2. Nilai Radian sensor tiap stasiun pengamatan

Pada gambar 2 tersebut dapat dilihat bahwa radian 2 sampai radian 5 memiliki pola yang sama. Hal tersebut memperlihatkan hasil kalibrasi radiometrik yang dilakukan tidak mengalami kesalahan dalam memasukkan data, nilai radian tertinggi yaitu radian 5 pada stasiun 16, sedangkan nilai radian terendah adalah radian 2 pada stasiun pengamatan 18 .

\section{B. Hasil Koreksi Atmosfer (Reflektan-Permukaan)}

Setelah nilai radiance ToA (Top of Atmospheric) diperoleh, maka selanjutnya dilakukan proses koreksi atmosfer menggunakan Second Simulation of a Satellite Signal in the Solar Spectrum-Vector (6SV). Adapun parameter 6s adalah sebagai berikut:

Tabel 1.

Parameter 6sv

\begin{tabular}{cccc}
\hline \hline Kanal & $\mathbf{X a}$ & $\mathbf{X b}$ & $\mathbf{X c}$ \\
\hline 2 & 0,00316 & 0,19157 & 0,21279 \\
3 & 0,00311 & 0,11316 & 0,17251 \\
4 & 0,00337 & 0,07208 & 0,14192 \\
5 & 0,00467 & 0,03690 & 0,09959 \\
\hline \hline
\end{tabular}

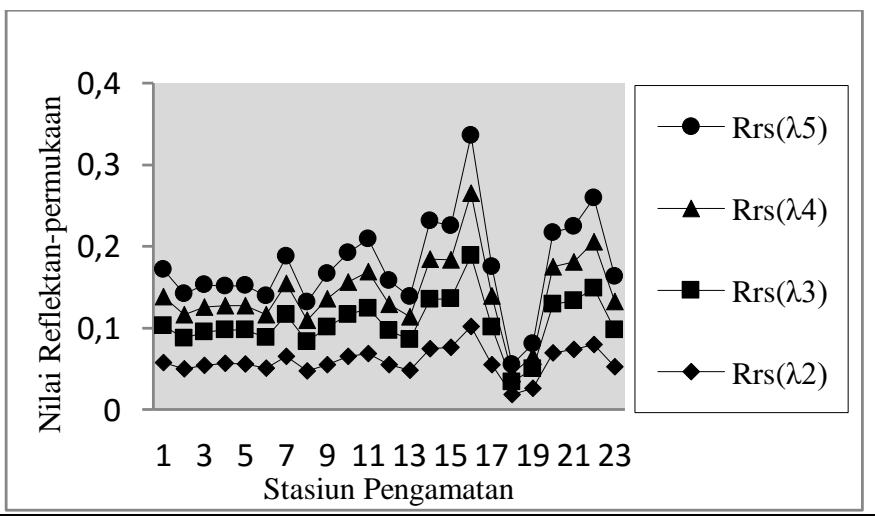

Gambar 3. Nilai Reflektan tiap stasiun pengamatan

\section{Hasil Akurasi Algoritma}

Berikut didapatkan hasil akurasi algoritma menggunakan Normalized Mean Absolute Error (NMAE) Algoritma TSS:

Tabel 2.

Hasil NMAE Algoritma TSS

\begin{tabular}{ccc}
\hline \hline No & Algoritma TSS & NMAE $(\%)$ \\
\hline 1 & Laili (2015) & 92,778 \\
2 & Jaelani (2015) & 91,836 \\
3 & Parwati(2014) & $\mathbf{4 7 , 3 1 2}$ \\
\hline \hline
\end{tabular}

Dari hasil perhitungan NMAE tersebut NMAE terbaik adalah NMAE algoritma Parwati (2014) memiliki nilai $N M A E$ 47, $312 \%$, dimana NMAE berada diatas syarat maksimum NMAE 30\% agar bisa digunakan untuk mengekstrak data kualitas air dari data penginderaan jauh. Hal ini bisa disebabkan karena antara waktu pengambilan data lapangan dengan waktu pengambilan data citra berbeda, serta kondisi perairan yang mudah berubah. Nilai $N M A E$ yang $\leq 30 \%$ juga bisa di pengaruhi oleh proses koreksi atmosfer yang mengalami kesalahan dan kesalahan tersebut menjalar ke pengolahan citra menggunakan algoritma-algoritma tersebut.

Berikut adalah hasil akurasi algoritma Transparansi menggunakan Normalized Mean Absolute Error (NMAE):

Tabel 3 .

Hasil NMAE algoritma Transparansi

\begin{tabular}{ccc}
\hline No & Algoritma TSS & NMAE $(\%)$ \\
\hline 1 & Shodiqin (2015) & 40,825 \\
2 & Tarigan (2012) & $\mathbf{1 0 , 8 4 3}$ \\
3 & Chipman (2014) & 75,075 \\
\hline \hline
\end{tabular}

Dari hasil perhitungan NMAE tersebut NMAE terbaik adalah NMAE algoritma Tarigan (2012), dimana memiliki nilai $10,843 \%$, dimana $N M A E$ masih berada dibawah syarat maksimum NMAE 30\% agar bisa digunakan untuk mengekstrak data kualitas air dari data penginderaan jauh. Hal ini bisa disebabkan karena kondisi daerah penelitian Tarigan (2012) memiliki karakteristik yang sama dengan lokasi penelitian ini.

\section{Pemetaan Konsentrasi TSS dan Transparansi}

Setelah melakukan koreksi radiometrik, selanjutnya melakukan pemetaan konsentrasi TSS dan transparansi menggunakan algoritma yang sudah ditentukan (1) dan (2). Konsentrasi TSS yang didapatkan memiliki rentang nilai 0 $\mathrm{mg} / \mathrm{l} \mathrm{sampai} 45 \mathrm{mg} / \mathrm{l}$. Konsentrasi TSS di daerah dekat dengan daratan memiliki nilai diatas $21 \mathrm{mg} / \mathrm{l}$ yang menunjukkan bahwa ada pengaruh sedimentasi dari aktifitas manusia seperti limbah rumah tangga, pertanian, ataupun kegiatan tambang bauksit, pasir dan sebagainya. Konsentrasi TSS yang besar akan mengakibatkan terjadi kekeruhan didaerah tersebut. Selain itu, meskipun kondisi TSS di perairan Bintan tinggi namun masih sesuai dengan ambang batas pada Baku Mutu No.51 Tahun 2004. 


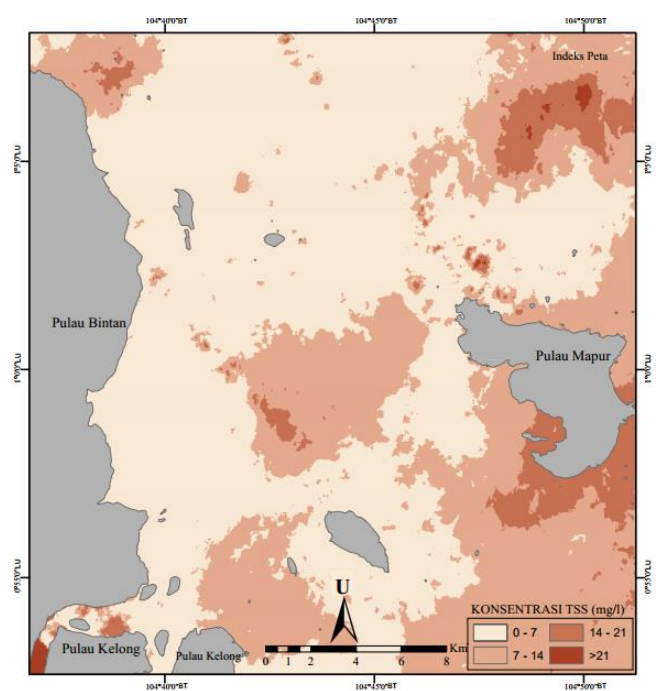

Gambar 4. Sebaran Konsentrasi TSS

Sedangkan sebaran transparansi diperairan Bintan Timur adalah sebagai berikut :

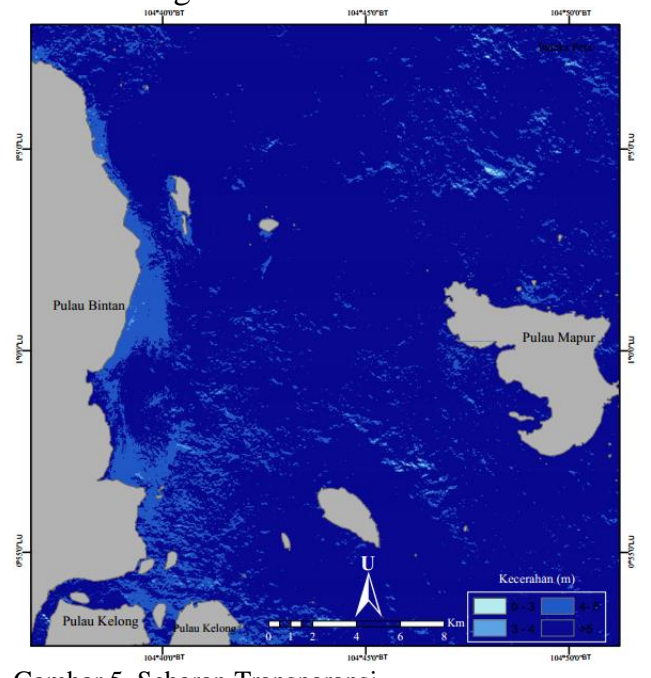

Gambar 5. Sebaran Transparansi

Dari gambar 6 transparansi diperairan Bintan memiliki rentang nilai antara $3-6$ meter. Kondisi transparansi perairan seperti berikut masih sesuai untuk kehidupan biota laut dan juga untuk kepeningan pariwisata. Transparansi di dekat perairan memiliki nilai yang rendah, itu berarti kekeruhan dan TSS meningkat.

\section{DAFTAR PUSTAKA}

[1] Pranowo, W. S. \& Husrin, S. in Kondisi Ekosistem Pesisir Pulau Bintan 34-39 (2003).

[2] Kepmen LH No 51. Keputusan Menteri Negara Lingkungan Hidup Tentang Baku Mutu Air Laut. 0, (2004).

[3] Liliesand, M. T. \& Kiefer, W. R. Penginderaan Jauh dan Interpretasi Citra. (Gadjah Mada University Press, 1979).

[4] Adriman, Purbayanto, A., Budiharso, S. \& Damar, A. Pengaruh Sedimentasi Terhadap Terumbu Karang di Kawasan Konservasi Laut Daerah Bintan Timur Kepulauan Riau. Berk. Perikan. Terubuk 41, 90101 (2012).

[5] Jaelani, L. M., Setiawan, F. \& Matsushita, B. Uji Akurasi Produk Reflektan-Permukaan Landsat Menggunakan Data In situ di Danau Uji Akurasi Produk Reflektan-Permukaan Landsat. Pros. Pertem. Ilm. Tah.
XX 2015467 (2015). doi:10.13140/RG.2.1.1391.9446

[6] Jaelani, L. M., Limehuwey, R., Kurniadin, N. \& Pamungkas, A. Estimation of TSS and Chl - a Concentration from Landsat 8 - OLI : The Effect of Atmosphere and Retrieval Algorithm. 27, 16-23 (2016).

[7] Laili, N.dkk. Development of Water Quality Parameter Retrieval Algorithms for Estimating Total Suspended Solids and Chlorophyll-a Concentration Using Landsat-8 Imagery At Poteran Island Water. ISPRS Ann. Photogramm. Remote Sens. Spat. Inf. Sci. II-2/W2, 55-62 (2015).

[8] Parwati, E. \& Purwanto, D. Analisis Algoritma Ekstraksi Informasi Tss Menggunakan Data Landsat 8 Di Perairan Berau. Semin. Nas. Penginderaan Jauh 2014 518-528 (2014).

[9] Shodiqin, A. M. Studi Total Suspended Solid dan Transparansi Perairan Menggunakan Citra Satelit Worldview 2 Sebagai Faktor Pembatas Pertumbuhan Terumbu Karang. (Institut Teknologi Sepuluh Nopember Surabaya, 2015).

[10] Tarigan, M. Aplikasi Satelit Aqua MODIS untuk Memprediksi Model Pemetaan Kecerahan Air Laut di Perairan Teluk Lada, Banten. ILMU Kelaut. Indones. J. Mar. ... 14, 126-131 (2012). 